NASA

Technical Memorandum 83725
USAAVSCOM

Technical Report 84-C-9

\title{
Efficiency of Nonstandard and High Contact Ratio Involute Spur Gears
}

Neil E. Anderson

Propulsion Laboratory

AVSCOM Research and Technology Laboratories

Lewis Research Center

Cleveland, Ohio

and

Stuart H. Loewenthal

Lewis Research Center

Cleveland, Ohio

Prepared for the

Fourth International Power Transmission and Gearing Conference sponsored by the American Society of Mechanical Engineers

Cambridge, Massachusetts, October 10-12, 1984

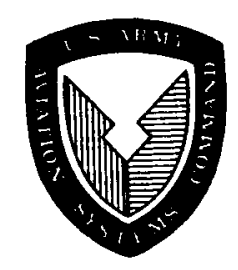


EFFICIENCY OF NONSTANDARD AND HIGH CONTACT RATIO INVOLUTE SPUR GEARS

\author{
Nełl E. Anderson* \\ Propulsion Laboratory \\ AVSCOM Research and Technology Laboratories \\ Lewis Research Center \\ Cleveland, Ohio 44135 \\ and \\ Stuart H. Loewenthal \\ National Aeronautics and Space Administration \\ Lewis Research Center \\ Cleveland, Ohio 44735
}

\title{
ABSTRACT
}

A power loss prediction method previously developed by the authors was extended to include involute spur gears of nonstandard proportions. The method can now be used to analyze the effects of modified addendum, tooth thickness, and gear center distance in addition to the parameters previously considered which included gear dlameter, pitch, pressure angle, face width, oil viscosity, speed and torque. Particular emphasis is placed on high contact ratio gearing (contact ratios greater than two). Despite their higher siding velocities high contact ratio gears can be designed to levels of efficiency comparable to those of conventional gears while retaining their advantages through proper selection of gear geometry.

SYMBOLS LIST
a
addendum, $m$ (in.)
AR addendum ratio
$C_{1}$ to $C_{14}$ constants of proportionality
$F_{R} \quad$ rolling traction force, $N(1 b f)$

*Currently with Allison Gas Turbine Division, Indianapolis, Indiana 46206. 
$\mathrm{F}_{\mathrm{S}}$

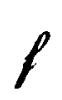

G

$\mathrm{H}_{\mathrm{H}}$

h

K

k

m

N

n

$P_{R}$

$\mathrm{P}_{\mathrm{S}}$

$P_{W}$

$\mathbf{R}$

U

V

$\mathrm{V}_{\mathrm{S}}$

$v_{T}$

W

$w$

$x$

Greek:

$\lambda$ sliding force, N (lbf)

face width of tooth, $m$ (in.)

coefficient of friction

dimensionless material parameter, E'o

dimensionless film thickness (eq. (4))

isothermal central film thickness, m (in.)

gear capacity factor $k=\frac{w\left(m_{g}+1\right)}{F D_{p} m_{g}}$

ellipticity parameter

gear ratio, $N_{g} / N_{p}$

number of gear teeth

rotational speed, rpm

power loss due to rolling traction, $\mathrm{kW}$ (hp)

power loss due to tooth sliding, $\mathrm{kW}(\mathrm{hp})$

power loss due to windage, kW (hp)

diametral pitch

pitch circle radius

dimensionless speed parameter

surface velocity, $\mathrm{m} / \mathrm{sec}$ (in./sec)

sliding velocity, $v_{g}-V_{p}, m / s e c(i n . / s e c)$

rolling velocity, $v_{g}+v_{p}, m / s e c(i n . / s e c)$

dimensiontess load parameter, $F_{H} / E^{\prime} R_{X}^{2}$

gear contact normal load, N (1bf)

path of contact distances

dimensionless ratio of film thickness to composite surface roughness 
$\boldsymbol{\mu}$

$\varphi_{t}$

\section{Subscripts:}

g

(

$R$

\section{Superscripts:}

$(-)$

average value

$$
\sec \left(1 \mathrm{n}^{2}\right)
$$

gear

pinion

rolling

sliding

\section{INTRODUCTION}

lubricant absolute viscosity, $10^{-3} \mathrm{~N} \mathrm{sec} / \mathrm{m}^{2}$ (cp) (1bf

thermal reduction factor

ambient conditions

Analytical evaluation of spur gears designs for efficiency has been rudimentary in the past due to the lack of a technique that could assess the many design variables $(1,2)$. In $(3,4)$ a technique was described that included the major design variables required for standard involute spur gears. In practice, however, gears are frequently designed with nonstandard proportions. These variations include modified addendums, tooth thickness variations and operation on nonstandard gear centers either by design or as a function of operating conditions. The analysis described in Refs. 3 and 4 is readily adaptable for these modifications and as such is the subject of this work.

A related subject is the analys is of high contact ratio (HCR) gears since they are actually one form of nonstandard spur gears. These gears have received much attention for use in aircraft application due to their increased load capacity and smoother operating characteristics (5-8). A major concern is whether or not they can be designed to provide equivalent efficiency while taking advantage of these benefits. This question can now be dealt with 
analytically with the extension of the standard gear power loss analysis to nonstandard gears.

GEAR POWER LOSS ANALYSIS

The method utilized here for calculation of efficiency was described in detail in Refs. 3 and 4 as applied to spur gears of standard proportions. It is applicable to spur gears which are jet or splash lubricated. Churning losses of gears running submerged in 011 are not considered. The analysis considers sliding losses, which are the result of friction forces developed as the teeth slide across each other, rolling losses resulting from the formation of an elastohydrodynamic (EHD) film and windage losses of both gears spinning in an ofly atmosphere.

The sliding and rolling losses were calculated by numerically integrating the instantaneous values of these losses across the path of contact. The friction coefficient used to calculate sliding loss was based on disk machine data generated by Benedict and Kelly (9). This friction coefficient expression is considered to be applicable in the EHD lubrication regime where some asperity contact occurs, that is, for $\lambda$ ratios less than two $(\lambda=$ ratio of minimum EHO film thickness to composite surface roughness). In Ref. 3 rolling losses were based on disk machine data generated by Crook (10). Crook found that the rolling loss was simply a constant value multiplied by the EHD central film thickness. Gear tooth film thickness was calculated by the method of Hamrock (11) and adjusted for thermal effects using cheng's thermal reduction factor (12). At high pitch line velocities isothermal equations such as Hamrock's will predict abnormally high film thickness since shear heating is not considered. Cheng's thermal reduction factor will account for the inlet shear heating and reduce the film thickness accordingiy. Inlet starvation effects are not considered. 


\section{Gear Power Loss Equations}

The equations developed in Ref. 3 are reviewed here and extended to include nonstandard and HCR gears. The method developed in Ref. 3 is limited to contact ratios less than two.

Figure $1(a)$ shows the tooth load distribution utilized in this analysis for gears with contact ratios between one and two. The teeth are assumed to be perfectly rigid and perfectly machined thus creating abrupt changes in tooth load as one or two teeth come into contact. The effect of contact ratio can be seen in this figure as the proportion of time that the load is shared by two teeth relative to that for one. Mesh two is being analyzed from start to finish but there are power loss contributions from mesh one and three that must be considered as we11. Figure $1(b)$ shows the analogous load distribution for contact ratios between two and three where either two or three teeth share the load. Here the tooth loads are lower due to the greater number of teeth sharing the load but now there are five mesh contacts contributing to the gearset power loss over one tooth mesh cycle.

The subject of actual tooth loading versus the assumed rigid profile is discussed in a later section. Contact ratios greater than three are not considered. Extension of the previous analysis to HCR gears was mainly a matter of being able to specify the additional changes in load as shown in Fig. 1(b). All basic equations other than the calculation of load are still applicable.

Sliding Force. - The instantaneous frictional force due to sliding of two gear teeth against each other is

$$
F_{S}(x)=f(x) w(x)
$$

The friction coefficient is calculated by the method of Benedict and Kelly (9)

$$
f(x)=0.0127 \log \frac{\frac{c_{1} w(x)}{G}}{\mu_{0}\left[v_{S}(x)\right]\left[v_{T}(x)\right]^{2}}
$$




$$
\begin{aligned}
C_{1} & =29.66 \text { (SI units) } \\
& =45.94 \text { (U.S. customary units) }
\end{aligned}
$$

Rolling Force. - The instantaneous force due to build up of the EHD film is

$$
\begin{gathered}
F_{R}(X)=C_{2} h(X) \varphi_{t}(X) F \\
C_{2}=9.0 \times 10^{7} \text { (SI units) } \\
=1.3 \times 10^{4} \text { (U.S. customary units) }
\end{gathered}
$$

The gear contact film thickness is calculated by the method of Hamrock and Dows on (11).

$$
H_{H}=\frac{h}{R_{X}}=2.69 u^{0.67}{ }_{G}^{0.53} W^{-0.067}\left(1-0.61 \mathrm{e}^{-0.73 k}\right)
$$

A thermal reduction factor, $\varphi t$, developed in Ref. 12 is used to limit $h$ at high speeds.

Sliding and Rolling Power Loss. - The instantaneous sliding and rolling power loss can be expressed as

$$
\begin{gathered}
\left.\begin{array}{c}
P_{S}(x)=C_{3} V_{S}(x) F_{S}(x) \\
P_{R}(x)=C_{3} V_{T}(x) F_{R}(x)
\end{array}\right\} \\
C_{2}=10^{-3} \text { (SI units) } \\
=1.515 \times 10^{4} \text { (U.S. customary units) }
\end{gathered}
$$


Average sliding and rolling power loss for contact ratios between one and

two. - The path of contact is divided into three sections corresponding to the changes in the normal load. The multiplication factors are due to the effects of load sharing as shown in Fig. 1(a).

$$
\begin{aligned}
& \bar{P}_{S}+\bar{P}_{R}=\frac{1}{x_{4}-x_{1}} \int 2 \int_{x_{1}}^{x_{2}}\left[P_{S}(x)+P_{R}(x)\right] d x \\
& \left.+\int_{x_{2}}^{x_{3}}\left[P_{S}(x)+P_{R}(x)\right] d x+2 \int_{x_{3}}^{x_{4}}\left[P_{S}(x)+P_{R}(x)\right] d x\right\}
\end{aligned}
$$

Average sliding and rolling power loss for contact ratios between two and three. - Here the path of contact is divided into five sections due to the more frequent changes in load.

$$
P_{S}+P_{R}=\frac{1}{x_{6}-x_{1}} \int_{x_{1}}\left[P_{S}(x)+P_{R}(x)\right] d x
$$


Windage Loss Expressions:

$$
\begin{aligned}
& P_{W . p}=c_{3}\left(1+2.3 \frac{F}{R_{p}}\right) n_{p}^{2.8} R_{p}^{4.6}\left(0.028 \mu+c_{4}\right)^{0.2} \\
& P_{W . g}=c_{3}\left(1+2.3 \frac{F}{R_{g}}\right)\left(\frac{n_{p}}{m_{g}}\right)^{2.8} R_{g}^{4.6}\left(0.028_{\mu}+c_{4}\right)^{0.2}
\end{aligned}
$$

\section{Modiftcation of Equations for Nonstandard Involute Spur Gears}

The additional features included in this analysis that allow calculation of nonstandard gears are: 1) addendum modifications maintaining pitch circle tooth thickness (modified cutter addendum); 2) addendum modifications accompanied by changes in pitch circle tooth thickness (tool shift); and 3) operation of gears on nonstandard center distances. Modifications to the dedendum or clearance do not affect efficiency as calculated above. A standard clearance of $0.35 / P$ was maintained throughout this investigation unless noted. Dedendum modifications may affect efficiency by altering the tooth load distribution but since a rigid tooth load pattern is assumed initially, the dedendum is not important. Tip round or profile modification was not considered directly but can be included in the form of a decreased addendum.

Pinion and gear addendums can be specified independently as follows:

$$
a=(A R+E R) / P
$$

where $A R=$ addendum ratio $=(a)(P)$ when $E R=0$

$$
\begin{aligned}
E R & =\text { tool shift ratio }=(e)(P) \\
e & =\text { actual tool shift }
\end{aligned}
$$

An addendum modified by a change in AR does not change the tooth thickness and is accomplished by using a cutter with a greater whole depth than standard. The gear blank outside diameter must be enlarged to allow for the extended addendum. Addendums can be increased by this method until the tip of the tooth 
becomes pointed (see Fig. 2(a)) or until the mating gear can no longer be fabricated due to cutter thickness. Modifications to the addendum by AR do not require a change in mounting distance.

The second method commonly used to increase or reduce the addendum is cutter tool shift where the cutter is held out to increase the addendum or held in to reduce the addendum. A tooth that is held out is thicker at the nominal pitch diameter (see Fig. 2(b)) resulting in a stronger tooth. If the pinion is held out by the same amount that the gear is held in, then the gears are referred to as long and short addendum gears. These gears will operate on the standard center distance but the operating pitch diameter will shift by the undercut in pinions with small numbers of teeth. Frequently, however, only the pinion is held out so that the pinion bending strength can be more closely matched to that of the gear. In this situation the mounting distance must be increased to allow for the difference in tooth thickness of the pinion.

The gear geometry equations were also modifled to account for operation at nonstandard center distances following Khiralla (13). The previously developed efficiency equations of Ref. 3 can still be used if the operating pressure angle and the operating pitch diameter are used in place of the nominal values. The effect of increasing the center distance from standard is to increase both the pressure angle and the pitch diameter. This results in increased backlash and lower contact ratio. Tool shift can be used to remove the backlash but the changes in pressure angle and pitch diameter remain.

The modified gear geometry equations were used to calculate the instantaneous rolling and sliding power loss at each point along the path of contact. The results presented in the following sections represent an average power loss obtained from a numerical integration of Eqs. 6 and 7. 
The power loss of HCR gears is calculated by Eq. 7. This equation represents a computer subroutine independent of that used by Eq. 6 for low contact ratio gears. As will be shown later the two subroutines produce continuous results passing from low to high contact ratios.

POWER LOSS OF NONSTANDARD GEARS

In Refs. 4, 14 and 15 the effects of many gear geometry and operating variables on efficiency were investigated. The purpose here is to determine the relative importance of the additional parameters considered above on gear power loss. To demonstrate these effects a low contact ratio gearset operating under a fully loaded condition $(K$-factor $=991)$ was selected. Using this gearset as a baseline, changes were made in addendum ratio, pressure angle, diametral pitch, center distance, tool shift ratio, diameter and overall gear ratio. Since calculation of efficiency of HCR gears is also an objective here, the effects of these parameters on contact ratio were also included. The baseline gearset selected here is gear L from Staph's analysis of HCR gears (16). It's geometry appears in Table I. This gearset geometry was chosen since it had the highest efficiency of the six Staph analyzed.

Addendum ratio - The effects of changing addendum ratio on power loss and contact ratio are shown in Fig. 3. This is one of two methods that are very effective in obtaining HCR gears. The HCR gear is not an unusual gear in that the addendum ratio need only be increased to 1.2 from the standard value of 1.0 to obtain a contact ratio of two if both pinion and gear addendums are modified equally. If only the pinion or gear are modified the dedendum ratio must be increased to 1.3. A problem with HCR gears in general is that the sliding velocities increases significantly as the contact ratio is increased as shown in Fig. 4. This increased sliding velocity leads to higher power loss even though the load is shared by three teeth instead of two during the high 
sliding phases. This is the reason for the steady increase in power loss as the addendum ratio increased. Higher surface temperatures are also predicted in Ref. 16.

Pressure angle - Another effective method of obtaining high contact ratio is a decrease the pressure angle. For the baseline gear $L$, the pressure angle at a contact ratio of two is approximately $19^{\circ}$. The length of the path of contact increases more rapidly than the base pitch as the pressure angle is decreased resulting in a higher contact ratio. Again the sliding velocity increases with increases in contact ratio resuiting in higher power loss (Fig. 5). Lowering the pressure angle also increases bending and compressive stresses because tooth thickness is reduced. Use of addendum ratio to obtain high contact ratio, on the other hand, actually lowers bending stress and only slightly increases compressive stress. A balance must be found between contact ratio and operating stresses for a given application.

Diametral pitch - In Fig. 5 the effects of changing diametral pitch are also shown. A constant pitch diameter of $12.7 \mathrm{~cm}$ was maintained while changing the number of teeth on the gears. The significantly lower power loss is due to the lower sliding velocities produced by the fine pitched gears. This lower power loss must be balanced by the increased bending stress found with finer pitched teeth. Compressive stresses do not increase as rapidly. Finer pitched gears have higher contact ratios than coarse pitched gears for the same pitch diameter but the effect of changing diametral pitch on contact ratio is not as great as changing addendum ratio or pressure angle.

A summary of the effects of addendum ratio, pressure angle and pitch on contact ratio are shown in Fig. 6 for a gear diameter of $10.2 \mathrm{~cm}$ and a gear ratio of 1. Similar results were obtained at a gear diameter of $406 \mathrm{~cm}$ except that all curves were shifted toward higher contact ratios. It appears that it is quite easy to obtain contact ratios greater than two with only slightly 
increased addendums for gears with pressure angles of $20^{\circ}$ or less. The $14.5^{\circ}$ pressure angle gear is basically an HCR gear. Finer diametral pitch also helps to increase contact ratio.

Nonstandard centers - Fig. 7 shows the effects of operating the baseline gearset on nonstandard centers. One curve shows the effects of simply extending the gear centers while allowing the backlash to increase and the other shows the effect of taking up the backlash by increasing tooth thickness with tool shift. The tool shift required to remove the backlash is very small (ER = 0.2 ) on both gears at a center distance offset of $0.5 \mathrm{~mm}$. The changes in power loss and contact ratio are relatively small especially if backlash is removed. By operating a standard gear at extended centers, the contact ratio decreases due to a shortening of the length of the path of contact and as a result power loss decreases.

Tool shift - The effect of operating a pinion fabricated with a large tool shift with a standard gear is shown in Fig. 8. In this case even though the contact ratio decreases there is a substantial increase in power loss, contrary to the trends found above. The higher losses are caused by shifting the standard load pattern from its symmetric position around the pitch point as shown in $\mathrm{Fig} .9$ (a) to a location that is skewed toward the recess side of the path of contact as shown in Fig. 9(b) (gear geometry based on gear $L$ ). This results in additional power loss due to the occurence of higher loads at points of higher sliding velocity. Also shown in Fig. 8 are the results of applying positive tool shift to the pinion and an equal amount of negative tool shift to the gear (long and short addendum gears). The results are the same for the same reasons. Use of tool shift as described above results in what is commoniy referred to as recess action (RA) gears. RA gears are generally considered to be more efficient than standard gears $(13,17-19)$, contrary to what was found here. This is often attributed to the sliding force vector 
assisting rotation during the recess phase. Tooth loading is predicted to be higher in the approach phase than in recess due to the reversal of the direction of the frictional sliding force when moving through the pitch point. A force balance of the teeth in mesh such as that done by Martin (18) shows how the sliding force adds to the normal load in approach and subtracts in recess. Consideration of this sliding force slightly increase the losses during the approach phase and reduce them during the recess phase but overall the reduction in losses extremely small. This can be seen in Fig. 10 where the instantaneous losses for gear $L$ modified for all recess action are calculated two ways 1) method using Eqs. 1-7 and 2) method described in (18) that considers the reversal of the sliding force. The reduction in loss due to the reversal of the sliding force is too small to offset the detrimental effect of load shift previousiy discussed.

Diameter and ratio - In Fig. 11 and 12 the effects of gear diameter and ratio on power loss are shown. Neither variable appreciably affects contact ratio. Power loss can be decreased by using a larger diameter gear to a point. Above $16 \mathrm{~cm}$, for this application, power loss begins to rise again due to increased rolling and windage 1055. If ratio is increased while center distance is maintained at $12.7 \mathrm{~cm}$, power loss increases dramatically. The pinion decreases in diameter as the gear increases. This situation causes increased sliding velocities and thus increased power loss.

Contact ratio - In Fig. 13 the effect of contact ratio on power loss is shown utilizing the data discussed above. A smooth transition in power loss is apparent as the contact ratio passes through two indicating convergence of the solutions from Eqs. 6 and 7. High contact ratios were mainly obtained by addendum elongation through an increase in $A R$ and by decreasing the pressure angle. Other parameters had little affect on contact ratio. It is apparent 
that power loss increases in going from low to high contact ratio. However, several other parameters can sharply increase losses without changing contact ratio such as diametral pitch, diameter and ratio. It cannot be said in general that increasing contact ratio results in higher losses but rather the changes in power loss is dependent on the method of changing contact ratio. HIGH CONTACT RATIO GEARS

In (16) Staph analyzed six gearsets including two low contact ratio $(1.8)$ and four HCR (2.2-2.4) variations. All were sized for the same application. The gear geometries are shown in Table I. The method described here was used to calculate the power loss of these gears as function of torque at the speed Staph selected, $3000 \mathrm{rpm}(16)$. An ofl viscosity of $30 \mathrm{cp}$. was selected arbitrarily. The results are shown in Fig. 14. Gear $L$ was found to be the most efficient low contact ratio gearset and was thus selected as the baseline gearset in this investigation as stated earlier. of the two low contact ratio gears, the coarser pitched gear $F$ had the lower bending stress (see table I). Gear L, although significantly more efficient, had an unacceptable bending stress of $0.57 \mathrm{GPa}(83000 \mathrm{ps}$ i) due to the small fine pitched teeth. of the HCR gears, gears H, G and $M$ had acceptable stress levels. Gear $K$ is essentially gear $L$ with a slightly longer addendum. Since the contact ratio of $K$ is greater than two the normal loads are decreased and thus the bending and compressive stresses were lower than gear $L$ but still quite high. As shown in Fig. 14, gear $K$ has the lowest power loss of all gears except $L$. However, nefther of these gears have stress levels that would permit operation at these torque levels for any length of time. Of the remaining HCR gears, gears $G$ and $H$ had power loss only slightly greater than gear $F$. Gear $M$ had a power loss comparable to gear $F$ at full load but much greater loss at part load due 
to its relatively large diameter. This ranking of the gear losses is consistent with what Staph found in Ref. 16 even though the magnitudes are not the same. Since Staph did not consider rolling or windage losses his loss estimate for gear $M$ was much lower than shown here. The rolling and windage losses are quite significant for gear $M$ as shown in Fig. 14 resulting in high tare losses (losses independent of torque). When these losses are included, the advantage of using the larger diameter gear is diminished for applications that require extensive operation at less than full load.

From this analysis it appears that the HCR gear $H$ would be, overall, the best design of the six analyzed by Staph. Its stress levels are about 12 percent lower than gear $F$, the best low contact ratio gearset, while its predicted losses are about 15 percent higher. This suggests that if carefully designed, HCR gears can provide lower operating stresses than that of a corresponding low contact ratio gear while not greatly sacrificing efficiency.

In Ref. 7 a similar study was performed on candidate designs for helicopter main transmission gears to determine their suitability for alrcraft use. The spur gear designs selected for testing are shown in Table II (helical gears were also investigated). The method described above was applied to the gears at $K$-factors to 1200 and a pitch line velocity of $15.2 \mathrm{~m} / \mathrm{sec}(3000 \mathrm{fpm}$, $1910 \mathrm{rpm}$ ) as shown in Fig. 15. The gearset with the best efficiency was the fine pitched gear 30 with an extended addendum and with a rather low pressure angle of $17^{\circ}$. This HCR gear had a weaker tooth form than that of the standard gear and lower predicted losses, mainly due to its finer pitch (see Fig. 5(a)). Although the HCR gears were not tested for efficiency in Ref. 7 , HCR gear 31 did experimentally demonstrate an increase in load carrying capablitty relative to standard gear 29 due to the increased load sharing. Its predicted power loss shown in Fig. 15 is only slightly greater than that of gearset 29. Thus again it appears that a higher load capacity HCR gearset can 
be designed to replace a standard, low contact ratio gearset without a major sacrifice in efficiency.

\section{RIGID VERSUS FLEXIBLE TOOTH LOADS}

To this point tooth loads have been calculated based on the rigid tooth load pattern shown in Fig. 1. In Ref. 16 loads were calculated based on tooth deflection calculations and, in Ref. 7, measured with strain gages. These load patterns do not show abrupt changes as the teeth come in and out of mesh but rather a steady rise from no load to full load and back to no load. The calculated load pattern for gear $G$ is compared to the rigid pattern in Fig. 16 . Calculations based on this load pattern showed a significant difference in power loss since the loads are very low at the points of high sliding. This is because the tooth load pattern is concentrated near the pitch point of the deflected tooth where the sliding velocities, hence, power losses are lower. This can be seen in Fig. 17 which shows the instantaneous power loss distribution for the flexible gear is both lower in magnitude and more narrowly distributed than the rigid gear. The rigid tooth patterns assumed in this analysis give a common base for comparison of low and HCR gears, but appear to overestimate the expected losses.

\section{SUMMARY}

The prevlously developed method for calculating power loss of standard spur gears was extended to include nonstandard geometry of gears with elongated or shortened addendums. Addendum modification by cutter elongation or tool shift was treated as well as operation of the gears at nonstandard center distances. Emphasis was placed on methods to obtain high contact ratio gears and their effects on power loss. HCR gears designed by two sources were analyzed for power loss. The following conclusions can be drawn from this investigation: 
1) Higher load capacity HCR gears can be designed to replace standard gears with a modest increase in predicted power loss.

2) Addendum elongation and pressure angle reduction are the most effective means of increasing contact ratio with a corresponding increase in power loss. Use of fine pitched gears is less effective in increasing contact ratio but provides a small reduction in power loss.

3) Changes in center distance or small changes in tool shift have relative minor effects on both contact ratio and power loss. However, large increases in tool shift to produce long and short addendum or recess action gears will cause an increase in predicted power loss.

4) A reduction in theoretical power loss is obtained when tooth deflections are considered.

5) Power loss can be reduced by using larger diameter gears until rolling and windage losses begin to dominate. Increases in gear reduction ratio at a constant center distance cause a substantial increase in power loss.

\section{REFERENCES}

1. Shipley, E. E., "Loaded Gears in Action," Gear Handbook. McGraw-Hill 1962, pp. 14-1 to $14-60$.

2. Buckingham, E., "Efficiencies of Gears," Analytical Mechanics of Gears, Dover 1963, pp. 395-425.

3. Anderson, N. E., and Loewenthal, S. H., "Spur-Gear-System Efficiency at Part and Ful1 Load," AVRADCOM TR 79-46, Army Aviation Research and Development Command, Ft. Eustis, VA, Feb. 1980.

4. Anderson, N. E., and Loewenthal, S. H., "Design of Spur Gears for Improved Efficiency," Journal of Mechanical Design, Vo1. 104, Oct. 1982, pp. $767-774$. 
5. Townsend, D. P., Baber, B. B., and Nagy, A., "Evaluation of High-Contact Ratio Spur Gears With Profile Modification," NASA TP-1458, Sept. 1979.

6. Drago, R., "Heavy Lift Helicopter Brings Up Drive Ideas," Power Transmission Design, March, 1974, pp. 49-63.

7. Albert1, J. P. and Lemanski, A. J., "Investigation of Increased Load Capacity of Spur and Helical Gears with Increased Contact Ratio," D210-10190-(AD-876741), Boeing/Vertol Division, Philadelphia, PA, Oct. 1970.

8. Leming, J. C., "HCR (2+) Spur Gears," AGMA Report P209.11, American Gear Manufacturers Association, Arlington, VA, Apri1, 1977.

9. Benedict, G. H. and Kelly, B. W., "Instantaneous Coefficients of Gear Tooth Friction," ASLE Transactions, Vol. 4, No. 1, Apr. 1961, pp. 59-70.

10. Crook, A. W., "The Lubrication of Rollers. IV. Measurements of Friction and Effective Viscosity," Philosophical Transactions of the Royal Society (London), ser. A, Vol. 255, No. 1056, Jan. 17, 1963, pp. 281-312.

11. Hamrock, B. J., and Dowson, D., "Isothermal Elastohydrodynamic Lubrication of Point Contacts. III-Fully Flooded Results," Journal of Lubrication Technology, Vol. 99, Series F, No. 2, Apr., 1977, pp. 264-276.

12. Cheng, H. S., "Prediction of Film Thickness and Silding Frictional Coefficlent in Elastohydrodynamic Contacts," 1 st Design Engineering Technology Conference, American Society of Mechanical Engineers, New York, 1974, pp. 286-293.

13. Khiralla, T. W., On the Geometry of External Involute Spur Gears, GEARS, North Hollywood, Calif., 1976.

14. Anderson, N. E., and Loewenthal, S. H., "Comparison of Spur Gear Efficiency Prediction Methods," NASA-CP-2210, 1983. 
15. Anderson, N. E., and Loewentha 1, "Effect of Geometry and Operating Conditions on Spur Gear System Power Loss," Journal of Mechanical Design, Vol. 103, No. 4, Jan. 1981, pp. 151-160.

16. Staph, H. E., "A Parametric Analysis of High-Contact-Ratio Spur Gears," ASLE Transactions, Vo1. 19, No. 3, 1976, pp. 201-215.

17. Buckingham, E. K., "Recess Action Gears," Gear Design and Application, McGraw-H111 1967, Pp. 136-143.

18. Martin, K. F., "The Efficiency of Involute Spur Gears," Journal of Mechanical Design, Vol. 103, No. 4, Jan. 1981, pp. 160-169.

19. Radzimovsky, E. I., Mirarefi, A., and Broom, W. E., "Instantaneous Efficiency and Coefficient of Friction of an Involute Gear Drive," ASME Paper 72-PTG-13, July, 1972. 
TABLE I. - GEAR GEOMETRY AND OPERATING CONDITIONS OF STAPH'S GEARS [16]

[Speed $=3000 \mathrm{rpm}$, torque $=487 \mathrm{~N}-\mathrm{m}(4307 \mathrm{in} .-1 \mathrm{~b})$, gear rat10 $=1.0$.

\begin{tabular}{|l|c|c|c|c|c|c|}
\hline \multicolumn{1}{|c|}{ Parameter } & F & L & G & H & K & $M$ \\
\hline Number of teeth & 50 & 100 & 50 & 50 & 100 & 100 \\
Diametral pitch & 10 & 20 & 10 & 10 & 20 & 10 \\
Pressure angle & 22 & 22 & 15 & 22 & 22 & 22 \\
Diameter, cm & 12.7 & 12.7 & 12.7 & 12.7 & 12.7 & 25.4 \\
Face width, cm & 1.91 & 1.91 & 1.91 & 1.91 & 1.91 & 1.91 \\
Contact ratio & 1.81 & 1.80 & 2.26 & 2.25 & 2.25 & 2.38 \\
Addendum ratio & 1.1 & 1.04 & 1.1 & 1.4 & 1.32 & 1.4 \\
Tool shift ratio & 0. & 0. & 0. & 0. & 0. & 0. \\
K-factor at 487 N-m & 991 & 991 & 951 & 991 & 991 & 248 \\
Pitch line velocity, m/s & 20 & 20 & 20 & 20 & 20 & 40 \\
Maximum bend. stress, GPa & .34 & .57 & .34 & .30 & .48 & .24 \\
psi/1000a & 49 & 83 & 50 & 43 & 70 & 35 \\
Maximum comp. stress, GPa & 1.14 & .99 & 1.23 & 1.0 & 1.14 & .48 \\
psi/1000a & 166 & 144 & 179 & 145 & 166 & 70 \\
\hline
\end{tabular}

acalculated by Staph in [16].

TABLE II. - GEAR GEOMETRY OF BOEING VERTOL GEARS [7]

$[100$ percent test load $=829 \mathrm{~N}-\mathrm{M}(7338 \mathrm{in} .-1 \mathrm{~b})$, gear $\operatorname{rat} 10=1.0 .1$

\begin{tabular}{|l|c|c|c|}
\hline Parameter & VT-29 & VT-30 & VT-31 \\
Number of teeth & 35 & 78 & 54 \\
Diametral pitch & 6.5 & 13 & 9 \\
Pressure angle & 25 & 17 & 17 \\
Diameter, cm & 15.3 & 15.3 & 15.3 \\
Face width, cm & 2.54 & 2.54 & 2.54 \\
Contact ratio & 1.51 & 2.38 & 2.29 \\
Addendum ratio & 1.03 & 1.264 & 1.248 \\
Tool shift ratio & -.032 & -.074 & -.051 \\
K-factor at 829 N-M & 900 & 853 & 853 \\
Pitch line velocity, m/s & 15.2 & 15.2 & 15.2 \\
\hline
\end{tabular}




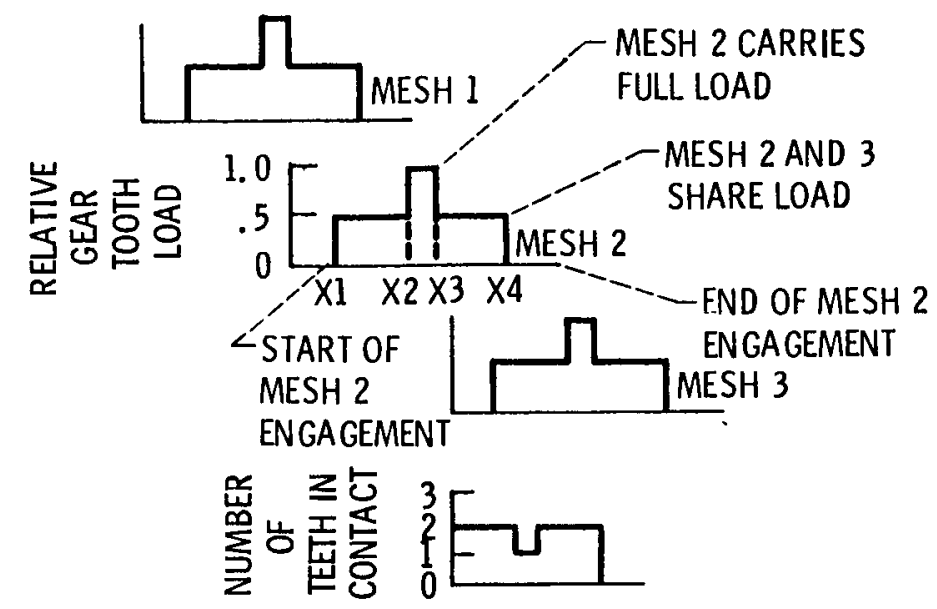

(a) Contact ratio between one and two.
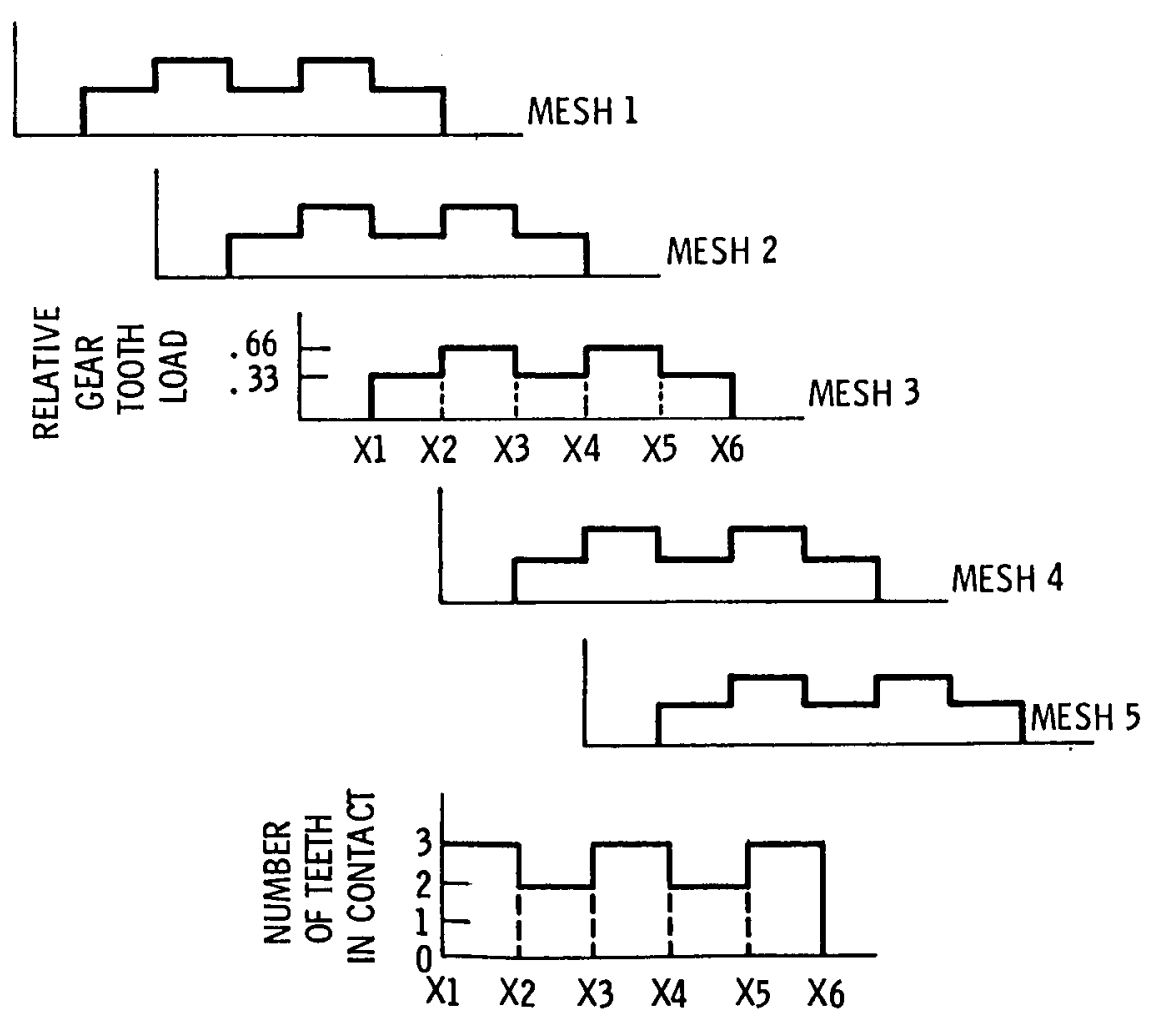

(b) Contact ratio between two and th ree.

Figure 1. - Tooth normal load distribution. 

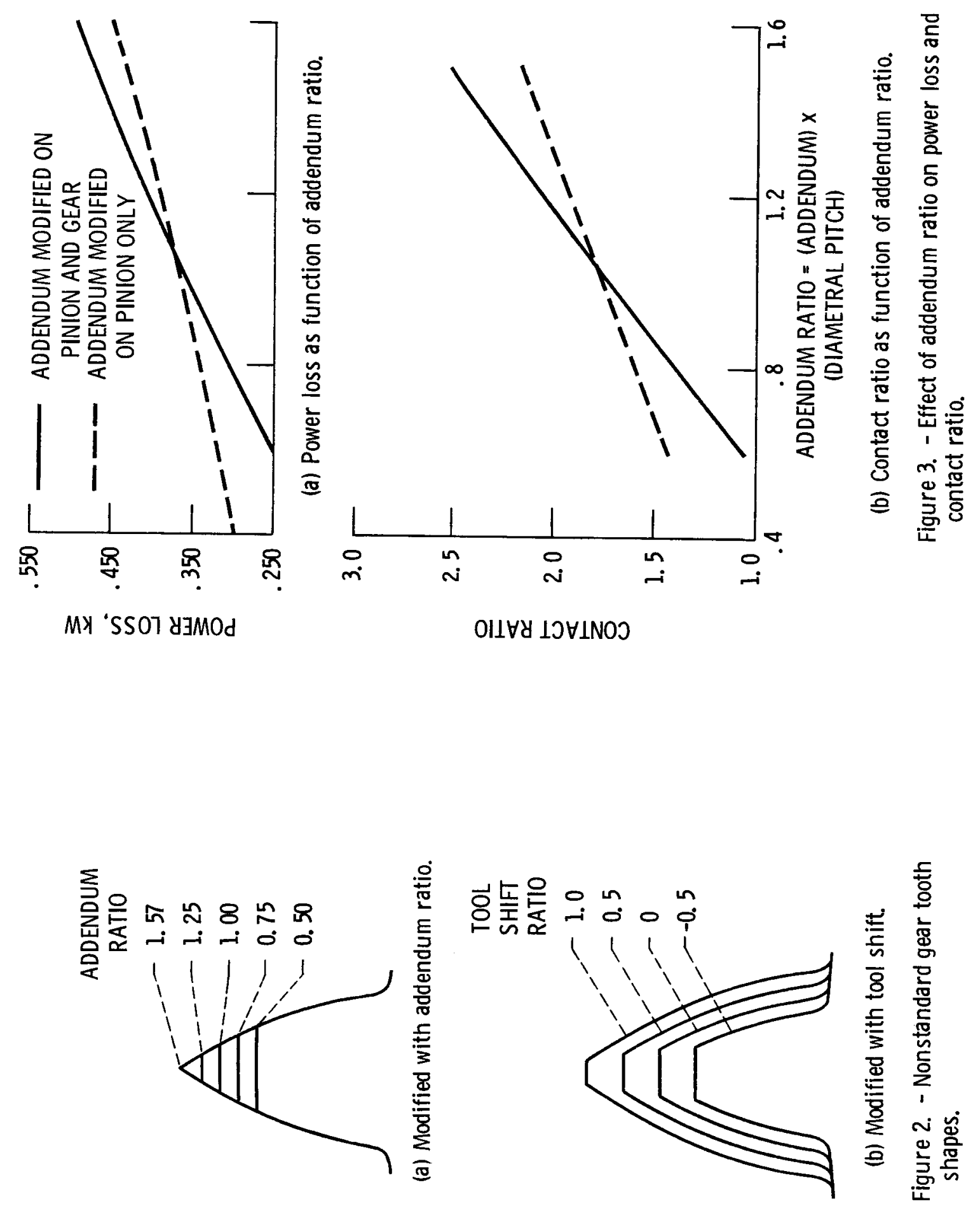


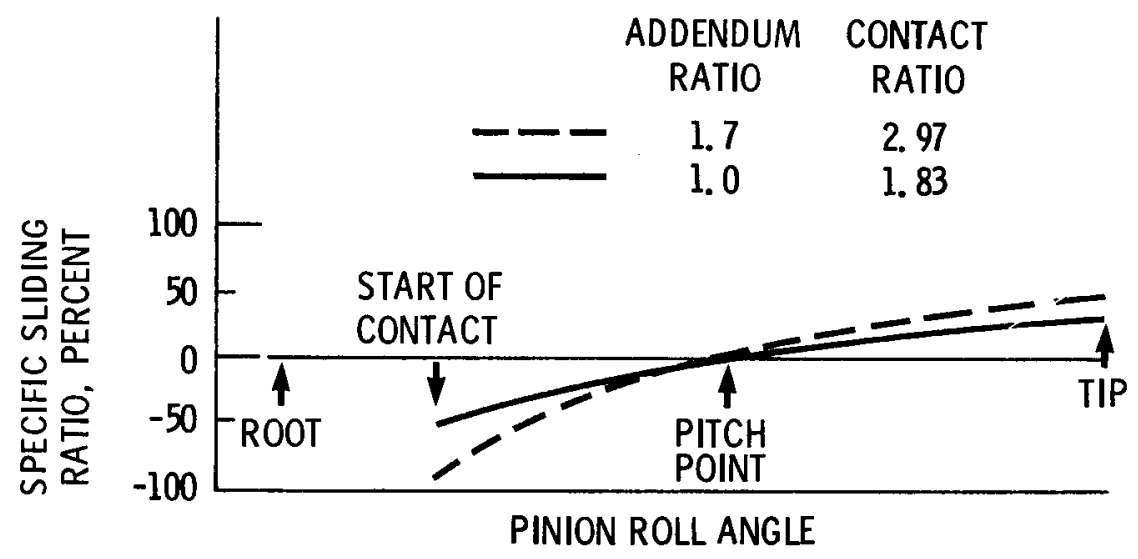

Figure 4. - Effect of addendum ratio on specific sliding. 


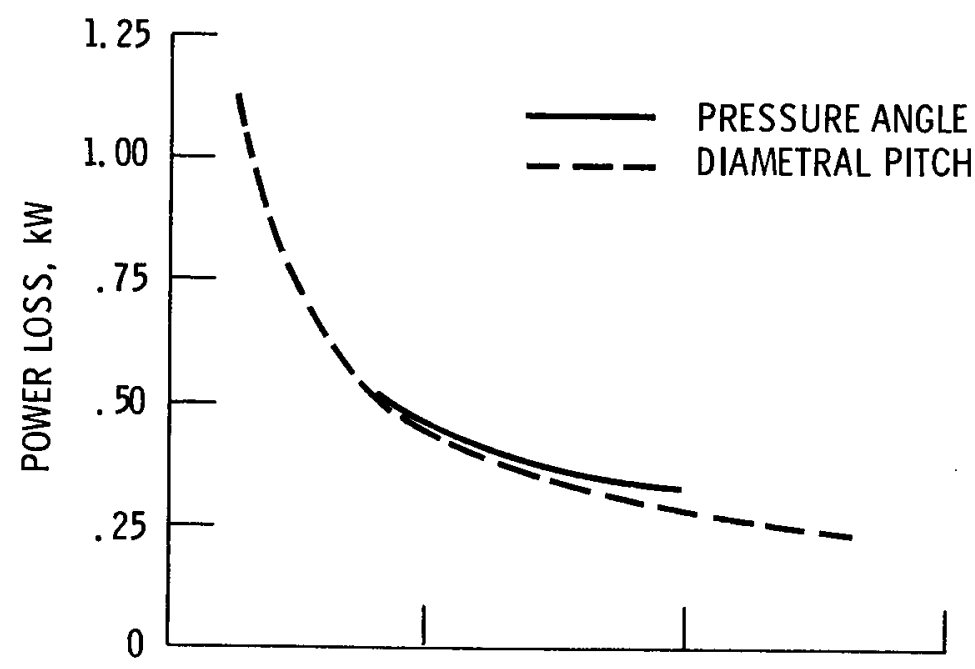

(a) Power loss as function of diametral pitch or pressure angle.

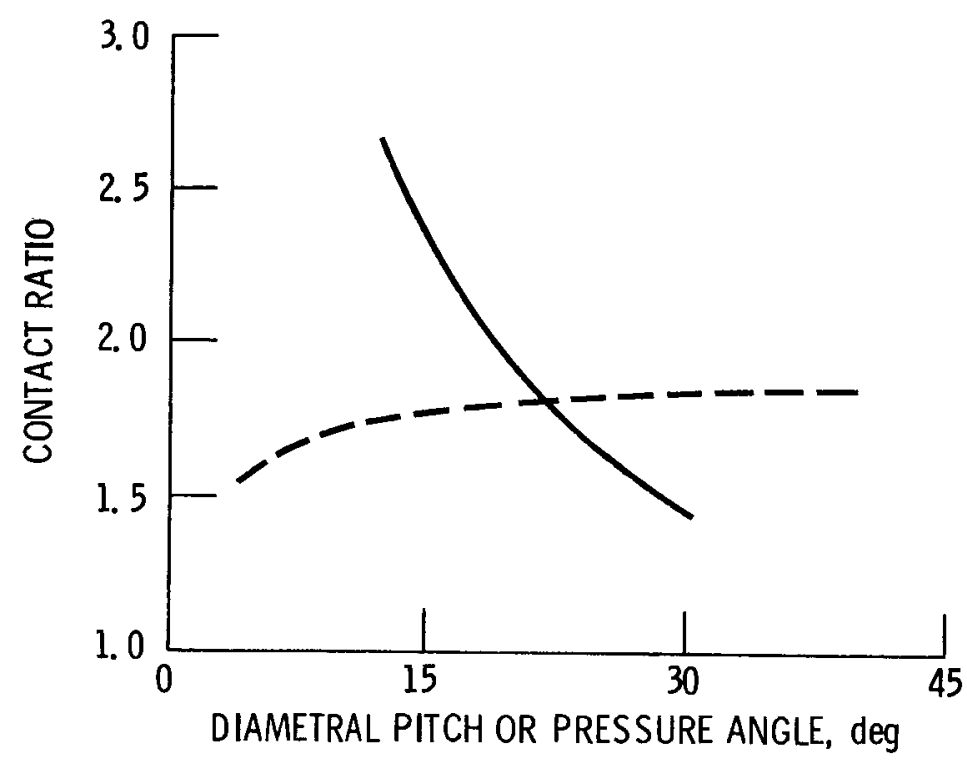

(b) Contact ratio as function of diametral pitch or pressure angle.

Figure 5. - Effect of diametral pitch and pressure angle on power loss and contact ratio. 

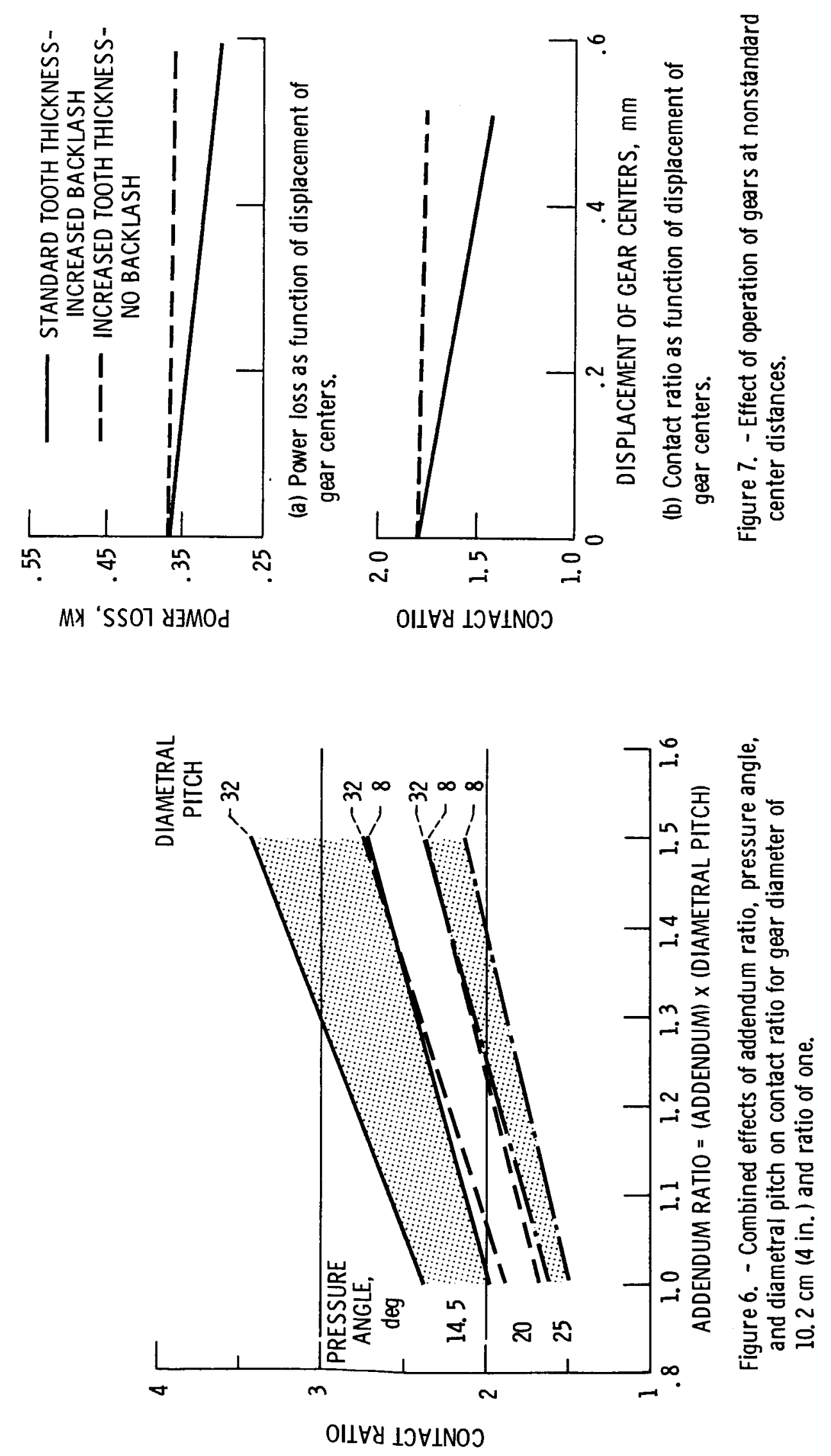


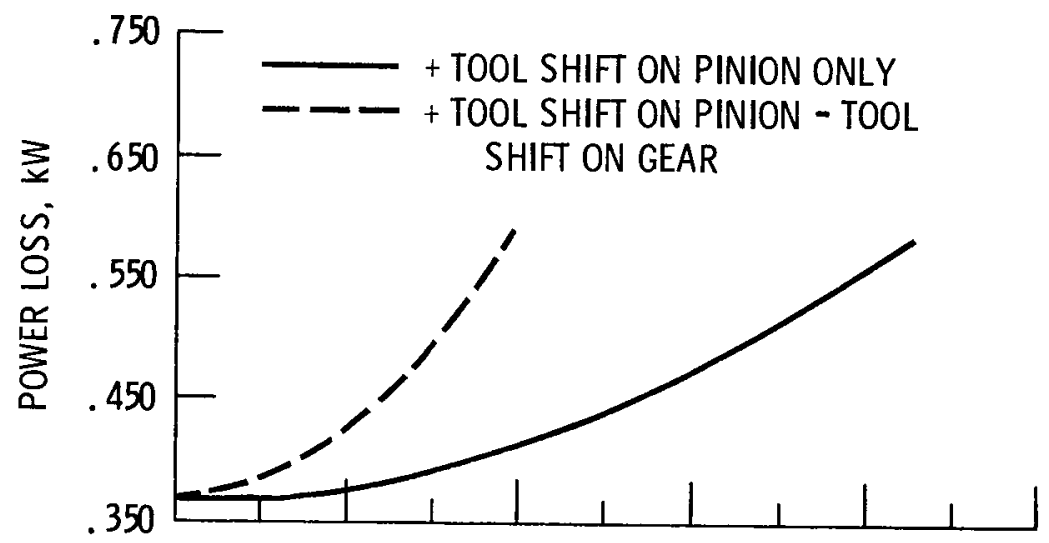

(a) Power loss as function of tool shift ratio.

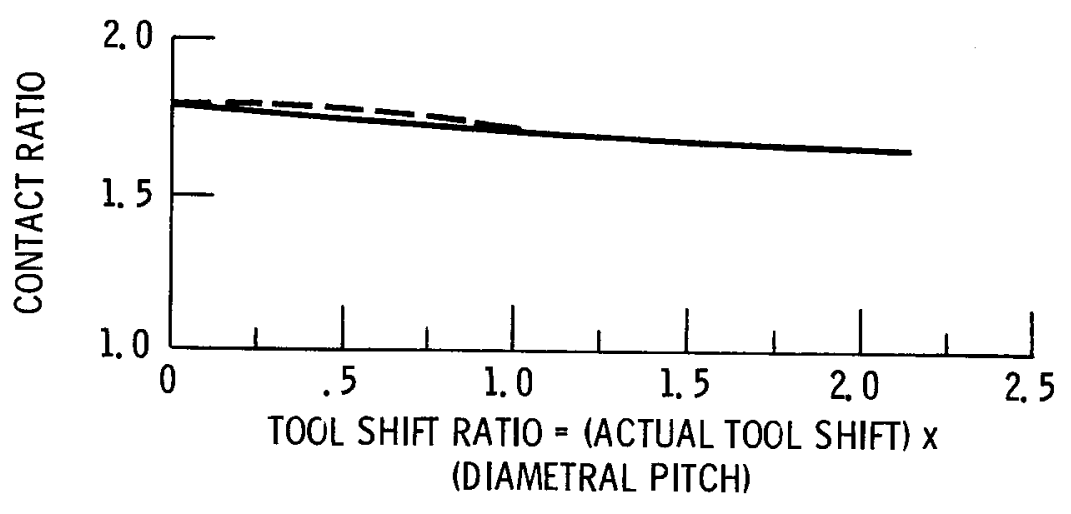

(b) Contact ratio as function of tool shift ratio.

Figure 8. - Effect of tool shift on power loss and contact ratio. 


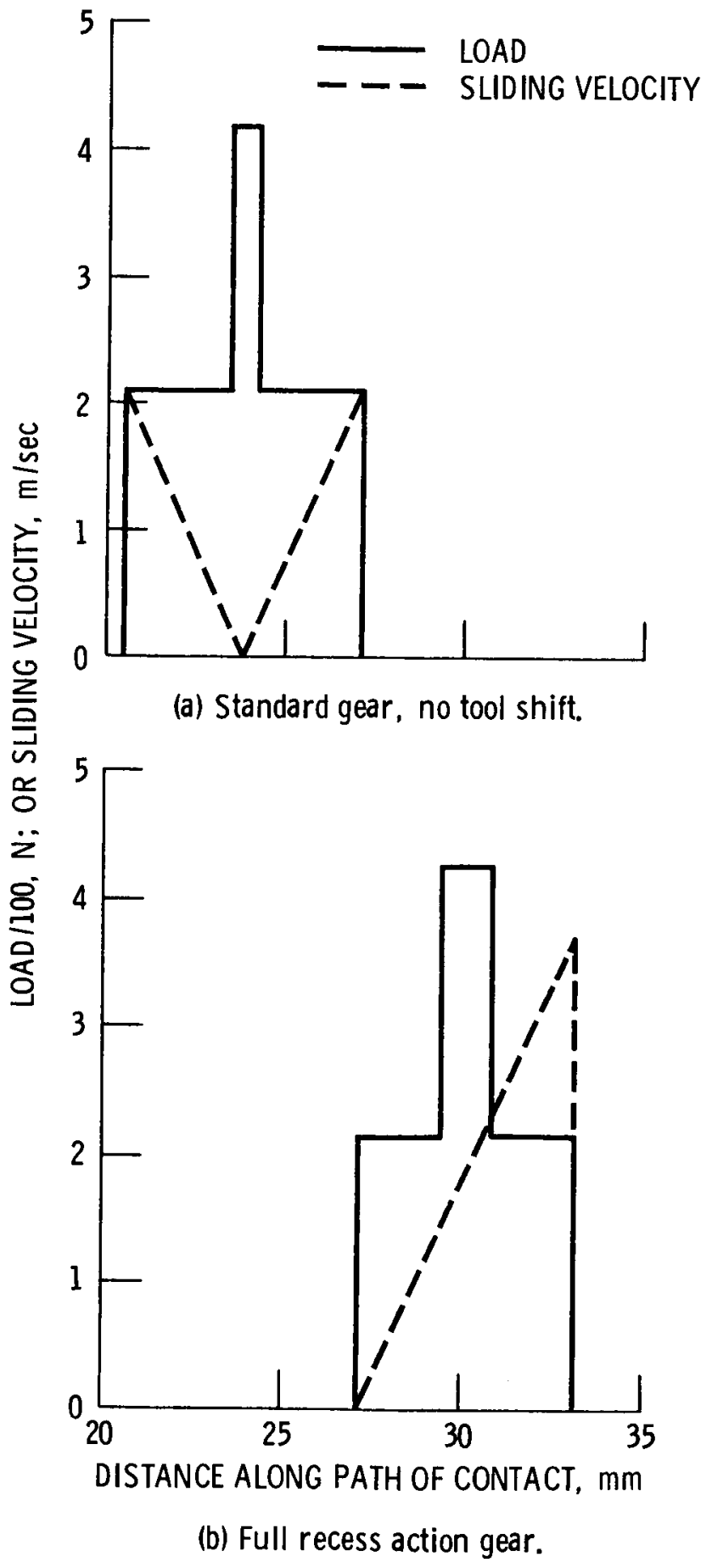

Figure 9. - Load distribution and sliding velocity of recess action gears as compared to its standard counterpart. 


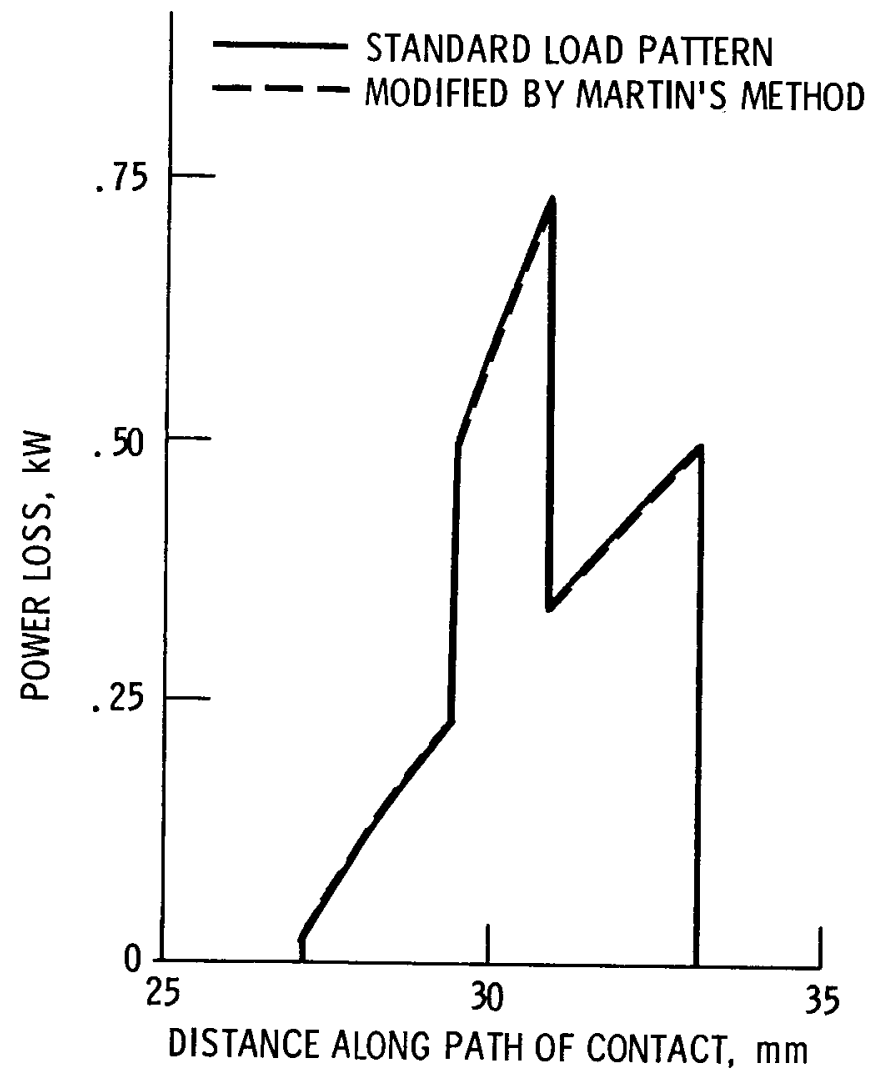

Figure 10. - Instantaneous power loss of a full recess action gear.

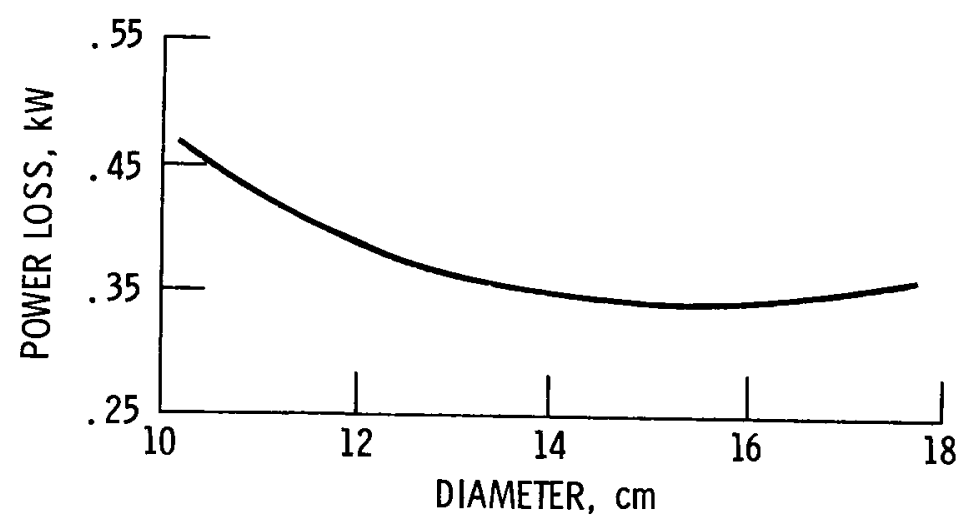

Figure 11. - Effect of gear diameter on power loss. 


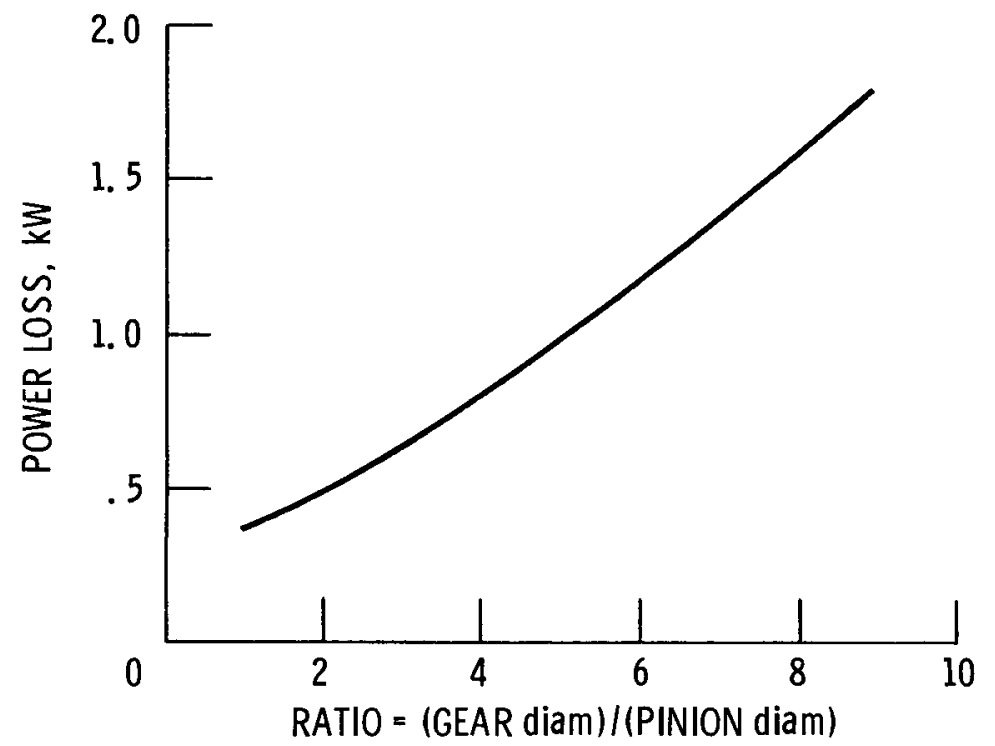

Figure 12. - Effect of gear ratio on power loss. Center distance was held constant at $12.7 \mathrm{~cm}$. 


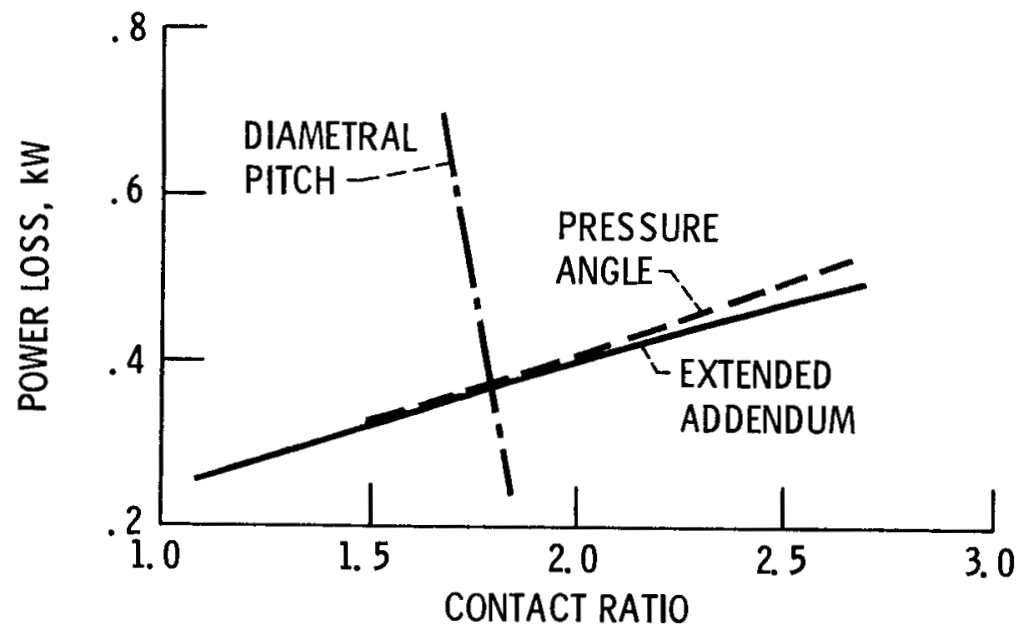

(a) Extended addendum, pressure angle and diametral pitch.

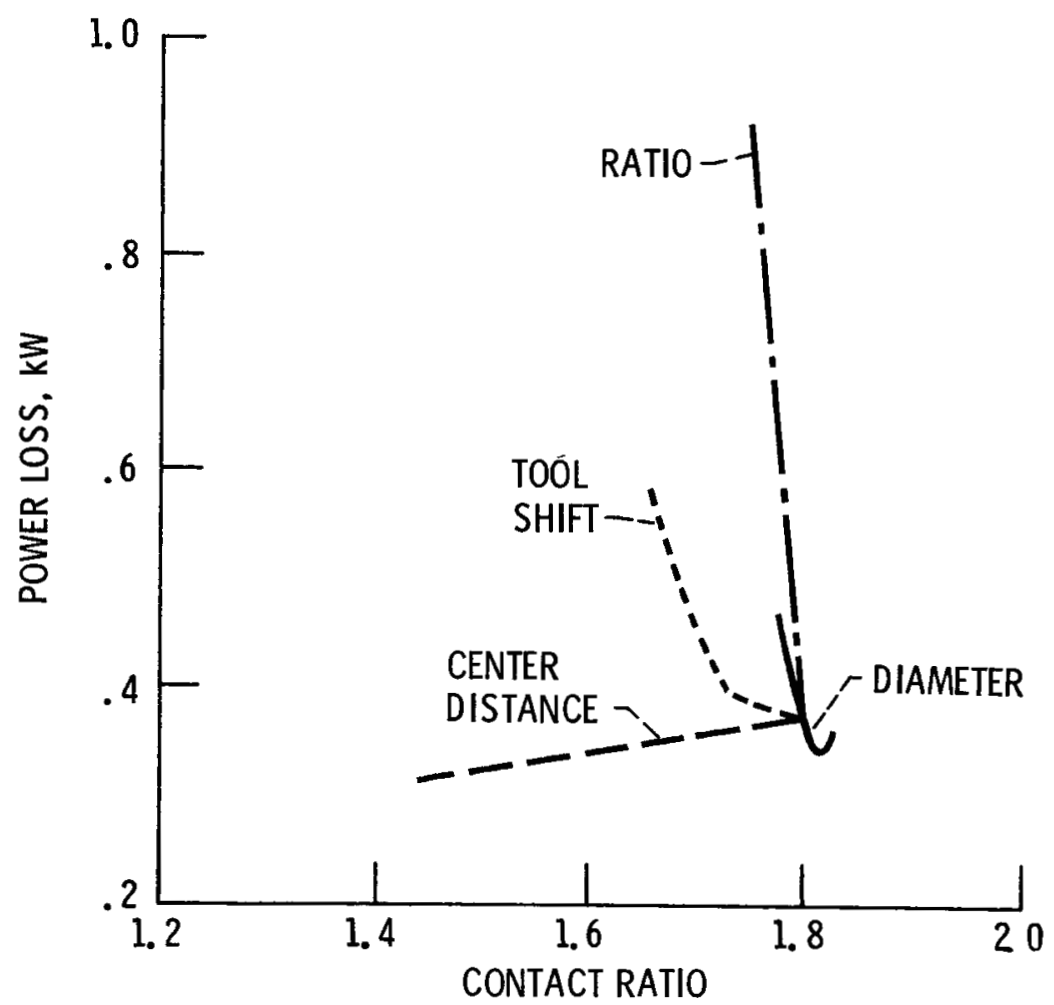

(b) Gear ratio, diameter, center distance and tool shift.

Figure 13. - Effect of contact ratio on power loss. 


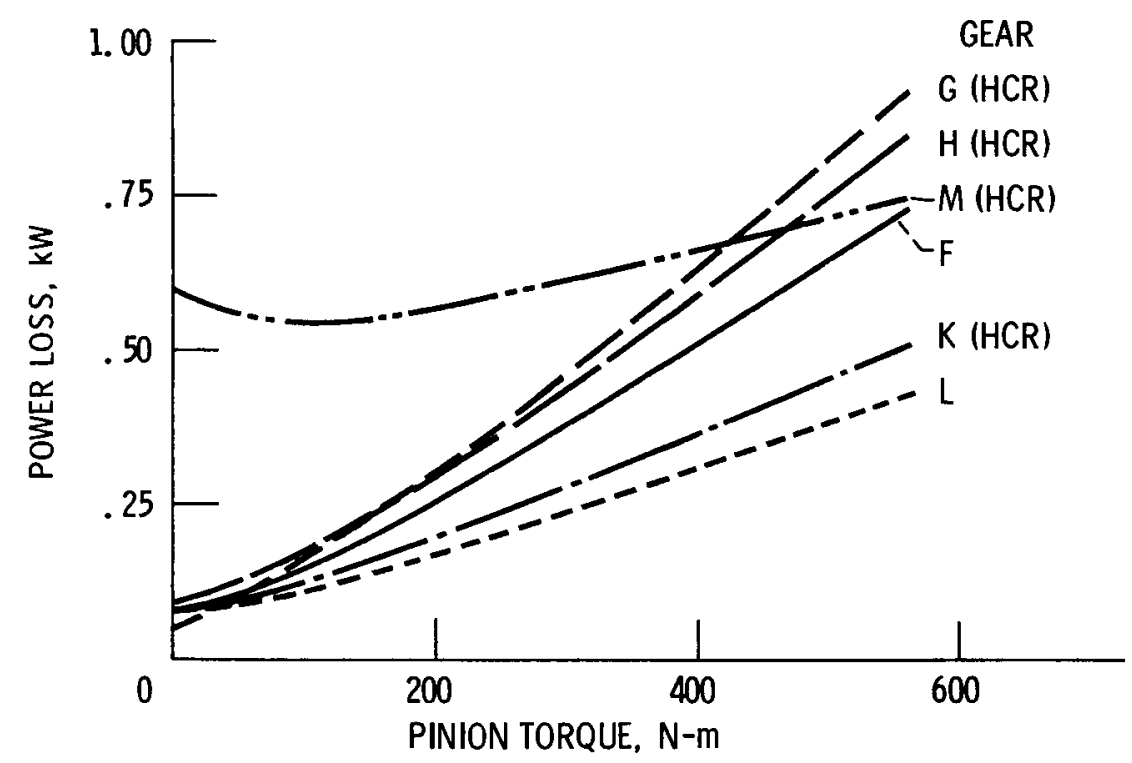

Figure 14. - Power loss of Staph's gears (see table I) at a constant speed of $3000 \mathrm{rpm}$ and oil viscosity of $30 \mathrm{cp}$.

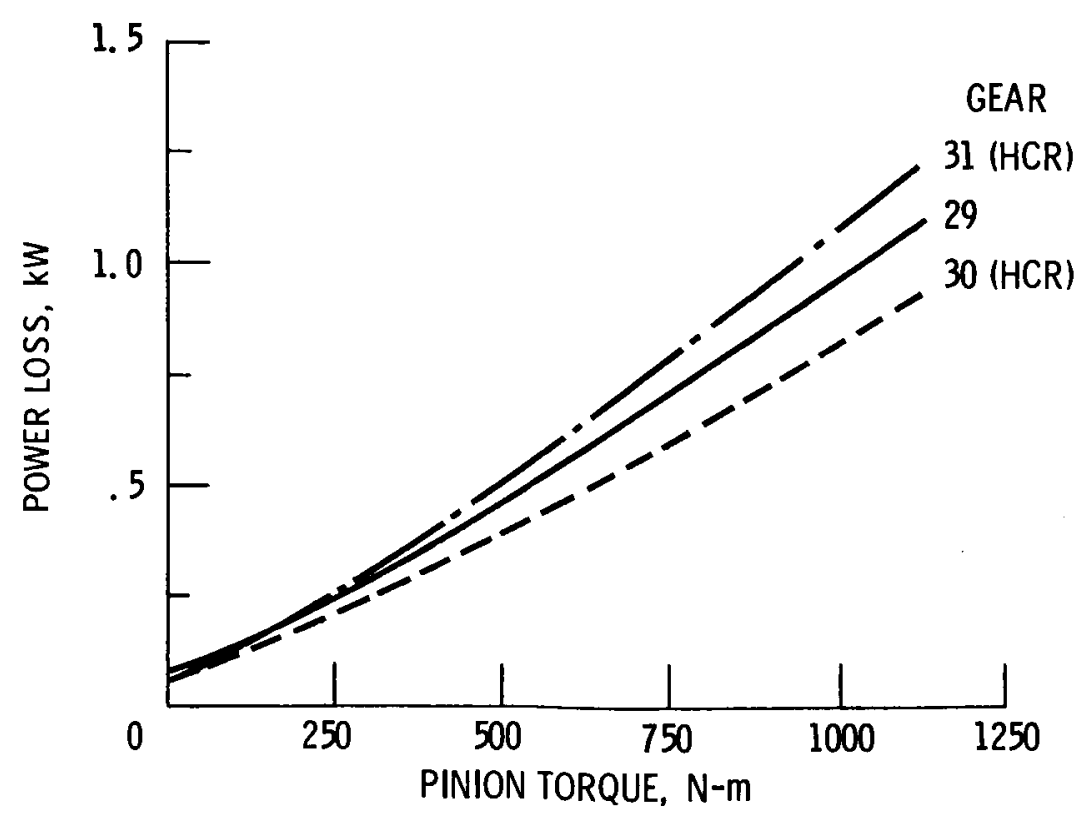

Figure 15. - Power loss of gears analyzed in [7] at 1910 $\mathrm{rpm}$ and an oil viscosity of $30 \mathrm{cp}$. 


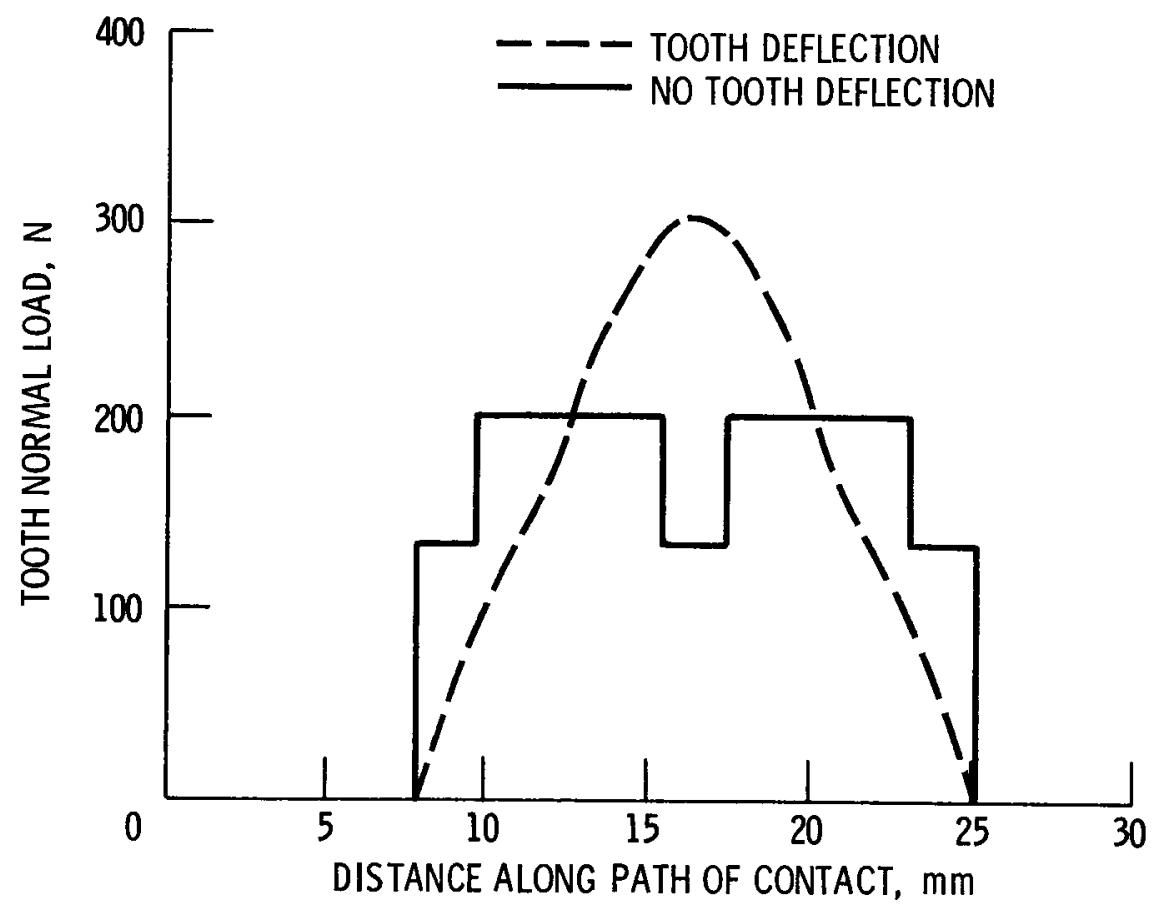

Figure 16. - Comparison of tooth load patterns assuming rigid and flexible teeth. 


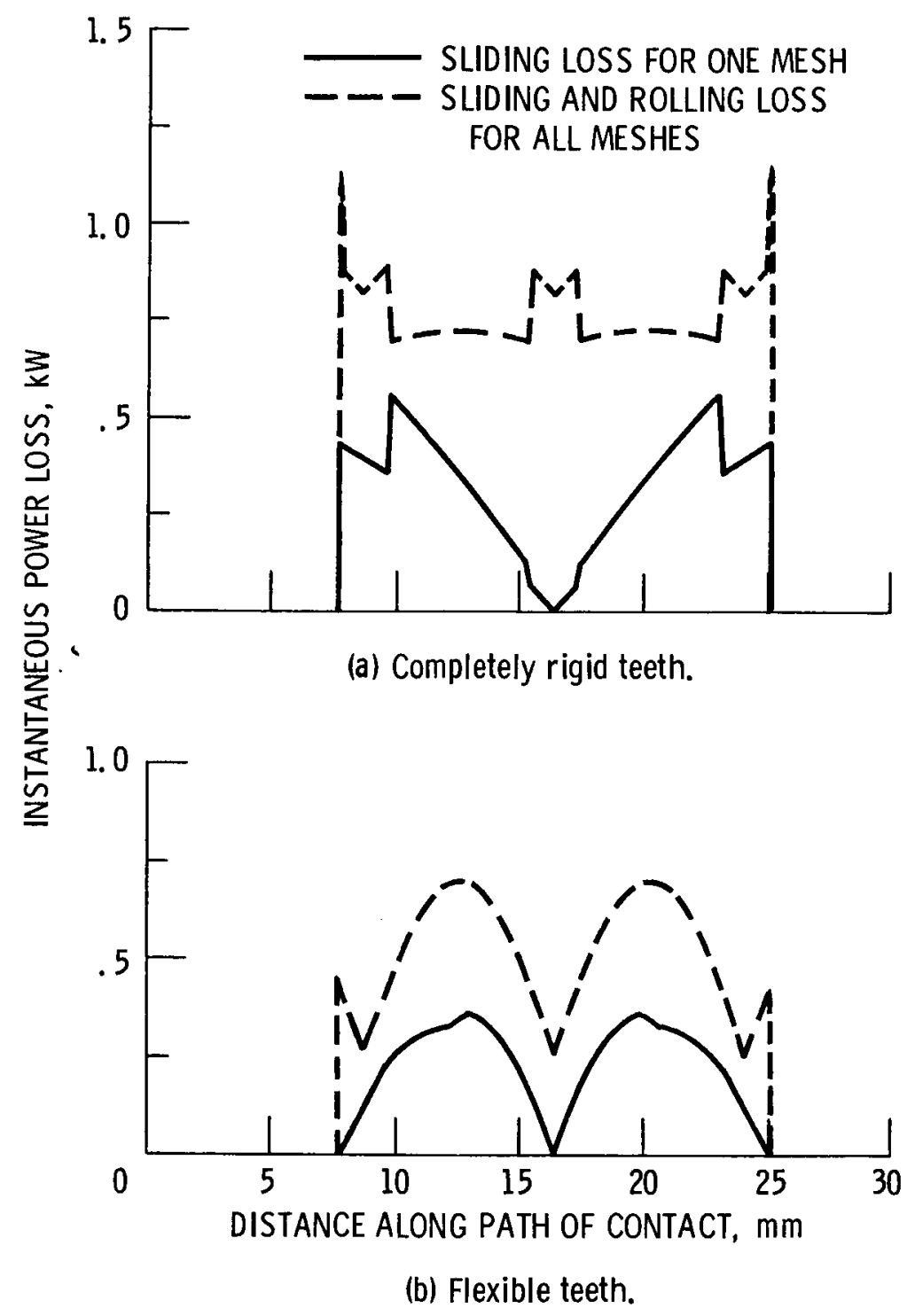

Figure 17. - Instantaneous efficiency based on load patterns for rigid and flexible teeth. Data is for gear $G$ (see table I) at $3000 \mathrm{rpm}, 486.6 \mathrm{~N}-\mathrm{m}$ (4307 in. - - b), and oil viscosity of $30 \mathrm{cp}$. 


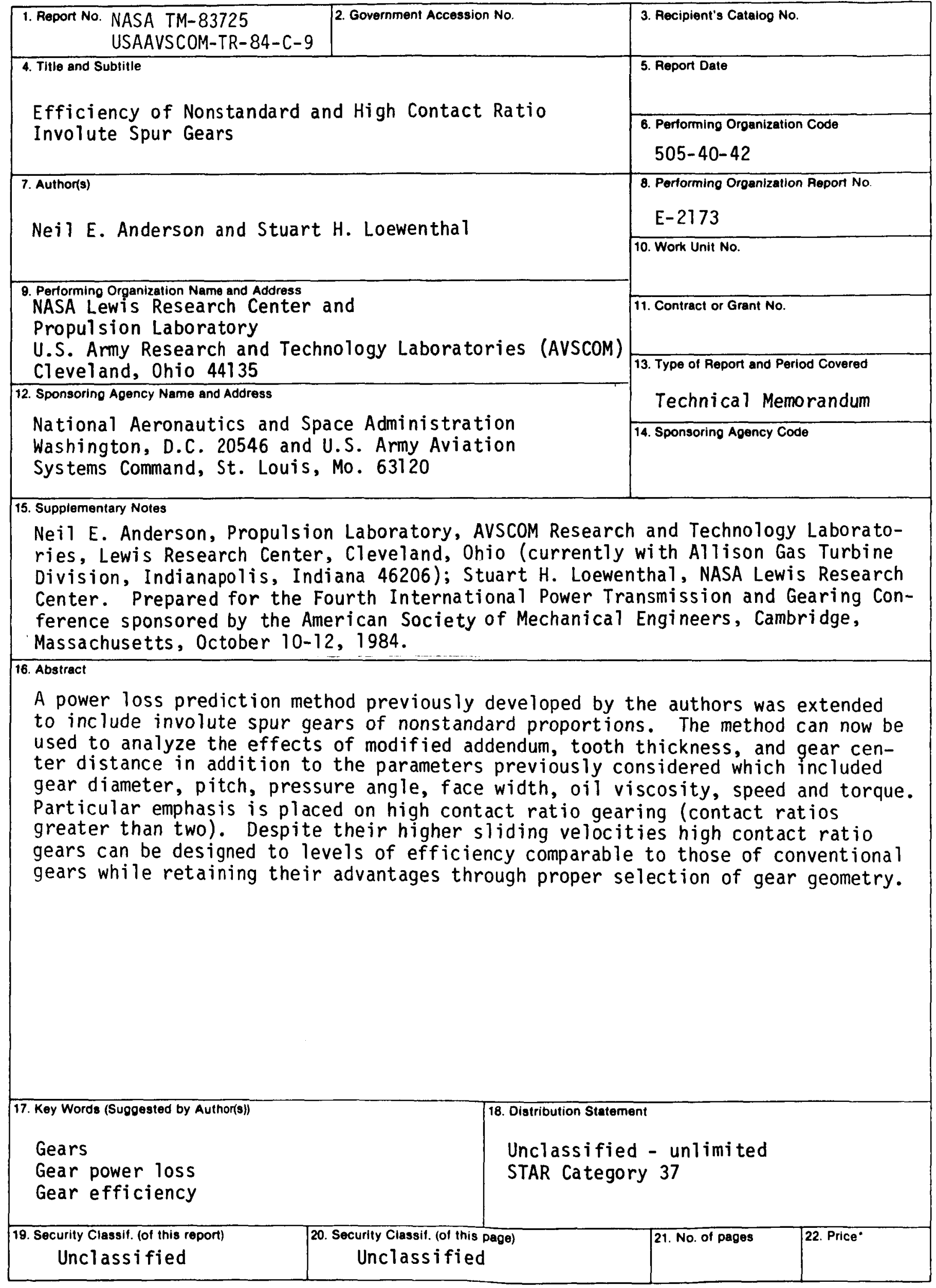

"For sale by the National Technical Information Service. Springfield, Virginia 22161 